\title{
Article \\ Modeling Analysis of SOFC System Oriented to Working Condition Identification
}

\author{
Xiao-Long $W u^{1,2, *}$, Hong Zhang ${ }^{1,3}$, Hongli Liu ${ }^{1}$, Yuan-Wu Xu ${ }^{4}$, Jingxuan Peng ${ }^{5}$, Zhiping Xia ${ }^{5}$ \\ and Yongan Wang ${ }^{6}$ D
}

1 School of Information Engineering, Nanchang University, Nanchang 330031, China; 6109119012@email.ncu.edu.cn (H.Z.); lhl318497@126.com (H.L.)

2 Shenzhen Research Institute, Huazhong University of Science and Technology, Shenzhen 518063, China

3 School of Mathematics and Computer Sciences, Nanchang University, Nanchang 330031, China

4 School of Information Science and Engineering, Wuhan University of Science and Technology, Wuhan 430081, China; xyw201314@hotmail.com

5 School of Artificial Intelligence and Automation, Huazhong University of Science and Technology, Wuhan 430074, China; pjx@hust.edu.cn (J.P.); d202080870@hust.edu.cn (Z.X.)

6 State Grid Hubei Maintenance Company, Wuhan 430050, China; wangyongancqu@126.com

* Correspondence: xiaolongwu@ncu.edu.cn or wx16895209@hust.edu.cn

check for updates

Citation: Wu, X.-L.; Zhang, H.; Liu, H.; Xu, Y.-W.; Peng, J.; Xia, Z.; Wang, Y. Modeling Analysis of SOFC System Oriented to Working Condition Identification. Energies 2022, 15, 1804. https://doi.org/ $10.3390 /$ en15051804

Academic Editor: Francesco Calise

Received: 16 January 2022

Accepted: 22 February 2022

Published: 28 February 2022

Publisher's Note: MDPI stays neutral with regard to jurisdictional claims in published maps and institutional affiliations.

Copyright: (c) 2022 by the authors. Licensee MDPI, Basel, Switzerland. This article is an open access article distributed under the terms and conditions of the Creative Commons Attribution (CC BY) license (https:// creativecommons.org/licenses/by/ $4.0 /)$.

\begin{abstract}
Solid oxide fuel cell (SOFC) generation system is an important equipment to realize "carbon neutralization". In SOFC system, a fault will cause changes in working conditions, which is difficult to detect early and find the reason due to the high temperature and seal environment. Therefore, the mechanistic model is a feasible way to find the reasons for the change of system working conditions. In this paper, based on the first law of thermodynamics, the system model of SOFC is built under multiple working conditions, and the influence of stack, afterburner, heat exchanger, and reformer fault is studied on the thermoelectric characteristics and efficiency of the system. The results show that with the introduction of these fault mechanistic models, the dynamic response characteristics of SOFC system under multiple working conditions can be obtained by tracking the key performance parameters qualitatively. The work of this paper is helpful for the guidance of the fault diagnosis of SOFC system in the future.
\end{abstract}

Keywords: solid oxide fuel cells system; system model; working condition identification; system analysis; energy conversion efficiency

\section{Introduction}

Global efforts to reduce greenhouse gases and harmful air pollutants require the development of clean and efficient energy conversion technologies [1,2]. Solid oxide fuel cells (SOFC) have the advantages of high energy conversion efficiency and low operating cost, which are widely considered as a promising alternative energy by industry experts and researchers [3,4]. However, one of the reasons that the SOFC system technology has not been used in large-scale generation is that it is difficult to identify system conditions and detect faults. Therefore, it is necessary to deeply analyze the working condition change mechanism of SOFC system, in order to solve the real-time working condition identification of SOFC system in high temperature sealing environment.

Installing a sufficient number of sensors is difficult for SOFC systems [5,6]. SOFC system belongs to the high temperature fuel cell system, and its key components are often concentrated in a highly sealed hotbox [7]. The installation of sensor not only affects the tightness of SOFC stack, but also affects the stack electrochemical reaction. Therefore, the mechanism of system working condition evolution can only be studied by modeling. Some scholars have studied SOFC stack and system modeling:

In terms of stack modeling, it is assumed that the stack operates in a constant temperature environment. Iwata built a quasi 2D (co-flow and convection) and 3D (cross flow) 
model for planar SOFC. In addition, the author studied the influence of physical characteristics, such as fuel recovery rate and gas pressure on temperature distribution, and showed that increasing the recovery ratio of gas and pressure can effectively inhibit the rise of temperature gradient [8]. Xi found that the four temperature layers (fuel flow, air flow, PEN) of SOFC stack are similar to the dynamic and steady state characteristics of two temperature layers (PEN and air flow), and a reduced order dynamic model was built to describe the conservation of material and energy in anode and cathode pipelines [9]. Furthermore, $\mathrm{Xi}$ analyzed the distribution and dynamic response of main parameters, such as temperature and current density in the gas pipelines, and carried out a simulation verification [10]. Chen used a two-dimensional model to study the internal reforming reaction of SOFC with ethanol as fuel [11]. Yan developed a two-dimensional model to analyze the effect of steam to carbon ratio on SOFC stack, and pointed out that it is necessary to consider the change of anode porosity when studying the carbon deposition of SOFC. Increasing the steam to carbon ratio can eliminate carbon deposition. However, the current density will decrease sharply [12]. Based on the aforementioned literature, the existing modeling of SOFC stack involves thermoelectric characteristics, which are the key parameters for identifying its working conditions. However, their models do not discuss the system working conditions. Therefore, it is difficult to investigate the change of SOFC stack working condition under constant temperature.

In SOFC system modeling, the existing work is mainly oriented to the hybrid generation system structure modeling and control-oriented modeling. Some scholars have deeply analyzed the performance of SOFC cogeneration system through the model. For example, Palomba simulated the energy saving and carbon dioxide emissions of cogeneration SOFC system through modeling [13,14]. Antonucci investigated the acceptable cost of sodium chloride nickel cell hybrid system using SOFC [15]. Krummrein proposed a detailed numerical model of hybrid system (SOFC + micro turbine), and discussed the influence of fuel cell operation limit on the operation range of hybrid power station, including stack temperature, minimum stack voltage, and maximum fuel utilization [16]. Lee used a simplified two-dimensional axisymmetric model domain to simulate the performance of a $1 \mathrm{~kW}$ fuel cell reforming unit. The results show that with the increase of fuel ratio, the formation rate of hydrogen and carbon monoxide increases. However, the increase rate decreases [17]. Maria built a three-dimensional model for SOFC/GT system to evaluate the operability of hybrid energy system based on SOFC and micro gas turbine. This method defines the operation range of the hybrid system, and finds the optimal operation parameters of load operation. The influence of fuel cell exhaust gas on the afterburner temperature response is verified based on CFD [18]. However, the relevant characteristic analysis of the independent SOFC system is disregarded. Chanon studied the effects of steam to carbon ratio, fuel utilization, temperature, and other key parameters on the current density, voltage, and heat production of SOFC through modeling. Additionally, the overall performance of SOFC integrated system is compared with the anode and steam cycles. In conclusion, the SOFC system with anode cycle has the higher electrical efficiency than SOFC system with steam cycle [19]. Park proposed an integrated system model based on SOFC and oxyfuel combustion technology. The system is improved from the hybrid system of supercharged SOFC gas turbine, which can capture $\mathrm{CO}_{2}$ almost completely and maintain high efficiency. The results show that the system efficiency of the integrated system is almost equivalent to the simplified SOFC gas turbine system [20]. Based on the aforementioned literature, the modeling research of SOFC hybrid energy system mainly focuses on the system efficiency, discharge characteristics, and temperature characteristics, which has a very important reference for the SOFC system mechanistic modeling in this paper.

However, the hybrid model mainly focuses on the response characteristics of integrated system, which is different from the system working conditions identification. It is necessary to increasingly focus on the subcomponents of SOFC system. Some scholars have carried out modeling research on system control problems. This kind of model pays significant attention to the subcomponents of the system. For example, Mueller built the 
SOFC system model, including SOFC stack, reformer, heat exchanger, afterburner, etc. The influence of stack operating temperature and fuel utilization rate was analyzed. The research shows that the average temperature of the stack can be effectively controlled by adjusting the cathode air flow rate [21]. Jiang identified a TS model for the reformer temperature after verifying the effectiveness of generalized predictive control algorithm for the SOFC system [22]. Yang proposed a TS fuzzy model based on the improved model, which can optimize the prediction model through training data [23,24]. Jiang selected the combined adjustment variables of air excess ratio and hydrogen utilization rate based on the SOFC system model with bypass valve with pure hydrogen. In addition, the author analyzed the dynamic and steady-state performance of the system using the hierarchical unconstrained map method, and determined the working range of the regulating variables and its dynamic influence on the system thermoelectric characteristics parameters in the dynamic switching process [25]. Zhang pointed out that there are many problems in the process of load tracking, and the optimization of SOFC thermal safety and efficiency is discussed based on the mechanistic model [26]. Based on the system mechanistic model, Cao revealed the influence of fuel utilization rate, air excess ratio, bypass opening, stack voltage on the system steady-state performance, and the dynamic response of system efficiency, stack inlet temperature, stack outlet temperature, and afterburner temperature [27]. The aforementioned literature has an important useful guideline for the SOFC system working mechanistic analysis, but the identification of system working conditions still needs to be further explored.

However, there are few reports on the modeling of SOFC system working conditions. In the existing reports, most of them focus on the coldbox components, such as blower. For example, Wu built the blower fault model [28], and Polverino built the controller fault, air leakage fault, and blower fault model to analyze the SOFC system performance [29-31], which only changed the system's external input and did not involve the change of thermoelectric characteristics caused by the system's internal fault. Table 1 presents the modeling methods aforementioned and their promotion to this paper. Therefore, it is necessary to model and analyze the working condition changes of SOFC system key components.

Table 1. Reference of different SOFC models.

\begin{tabular}{cccc}
\hline Model Type & Detailed Model & References & Function \\
\hline SOFC stack model & Thermoelectric model & {$[8-12]$} & $\begin{array}{c}\text { Analysis of stack thermoelectric } \\
\text { characteristics and working conditions }\end{array}$ \\
\hline System model & $\begin{array}{c}\text { Hybrid system model } \\
\text { Control system model }\end{array}$ & $\begin{array}{c}{[13-20]} \\
{[21-27]}\end{array}$ & Evaluation of system working conditions \\
\hline System fault model & $\begin{array}{c}\text { Coldbox model } \\
\text { Hotbox model }\end{array}$ & {$[28-31]$} & Evaluation of system fault conditions \\
\hline
\end{tabular}

In addition, the SOFC system fault is usually not sudden, but gradually evolves through the changes of system multiple transition phases in long-term abnormal operation $[32,33]$. There are multiple modes in the operation of any equipment, and there are also multiple modes in SOFC system. After introducing the concept of multimode, the difference of mode refers to the difference of working conditions. When it changes from one stable mode to another, it is often not achieved by direct switching. There is a transition stage in the process of transition. However, this gradual transition stage is often disregarded in the past research, which leads to the one sidedness of the research. Previous studies show that although the study of transition mode is often disregarded, it is a common and important phenomenon [34]. Therefore, this paper proposes a multimode SOFC system modeling method, which is mainly based on the energy conservation, mass conservation, Nernst voltage, and other mechanistic equations of each component. After integrating the system model, a complete SOFC system model is formed. Based on the built multimode mechanistic model of SOFC system, combined with the dynamic and steady state analysis, it is proposed to find the specific components of the fault through 
the performance of the system, in order to provide qualitative guidance for the working condition identification of SOFC system. The contributions of this paper are as follows:

- In the process of building the model, the multimode theory is introduced, which is helpful for the observation of the dynamic response characteristics of the system under different fault levels.

- In the process of fault modeling, the problems of stack performance degradation, afterburner gas flow rate instability, heat exchanger rupture, and reformer performance degradation are taken into account, which helps in deepening the understanding of system dynamic response under different working conditions.

The paper is organized as follows: Section 2 presents the overall framework of SOFC system and stack type. In Section 3, the SOFC system multimode modeling is completed and the results are obtained by the simulation in Section 4. Finally, in Section 5, the conclusions are presented.

\section{Overall Framework of SOFC System}

\subsection{Composition of SOFC System}

In the experiment, the research object is a $\mathrm{kW}$ class SOFC generation system experimental platform for the distributed power supply. The system structure is the efficiency optimization system structure obtained through calculation. The calculation is based on the load demand change of distributed generation, as well as the fuel flow rate, air flow rate, high temperature exhaust gas flow rate, steam to carbon ratio, and other parameters. Following the design and calculation, the natural gas SOFC system architecture suitable for the distributed generation is shown in Figure 1, and the SOFC system prototype is shown in Figure 2. The kW class SOFC system also integrates a set of BOP system to provide an external load. The auxiliary system is composed of reforming subsystem, hydrogen supply subsystem, air supply system, and afterburner subsystem. The natural gas is injected into the reformer through the pressure reducing valve. Hydrogen $\left(\mathrm{H}_{2}\right)$ and carbon monoxide (CO) are obtained by reforming deionized water and methane in the presence of Ru catalyst. The fuel gas enters the anode of SOFC stack after passing through the $\mathrm{CO}$ flow heat exchanger. The air enters the cathode of the stack through the convection heat exchanger (exhaust air heat exchanger) and the $\mathrm{CO}$ flow heat exchanger (fuel air heat exchanger).

In addition, the exhaust gas from the stack anode still contains a certain proportion of combustible materials. When it is mixed with the exhaust gas from the cathode, it will burn in the afterburner and release more heat. This increases the afterburner temperature and further utilizes or recovers the heat energy in the subsequent components. In addition, it reduces the release of harmful gas (CO). When the exhaust gas from the afterburner is released, it will balance with the normal temperature air in the convective heat exchanger to preheat the normal temperature gas to the high temperature range $\left(500-600{ }^{\circ} \mathrm{C}\right)$, which can improve the operation efficiency of SOFC system. In addition, the reaction between the SOFC stack and afterburner is exothermic, and the cooling water tank is used to absorb the underutilized waste heat of the system to heat the normal temperature water to realize the cogeneration, which is helpful for the further improvement of system efficiency.

Compared with the pure hydrogen SOFC system, the natural gas SOFC system needs to be equipped with desulfurizer, deionized water tank, water pump, and water evaporator (for mixing deionized water and natural gas, as well as high-temperature vaporization) to complete the reform for producing hydrogen. In this system, the uniformity of flow distribution is particularly important, but due to the variety of system components, the natural gas SOFC system shows strong coupling, which is more likely to cause the uneven system flow distribution, and affect the performance and lifetime of SOFC stack.

In Figure 2, the function of insulation cotton is to insulate the SOFC stack from the external environment, in order to ensure that the stack is in a working environment with a good insulation effect. In addition, to control the SOFC system temperature in a safe range, the temperature controller of the system sets the upper limit of heat source temperature. Specifically, the afterburner maximum temperature is not higher than $1200^{\circ} \mathrm{C}$. 


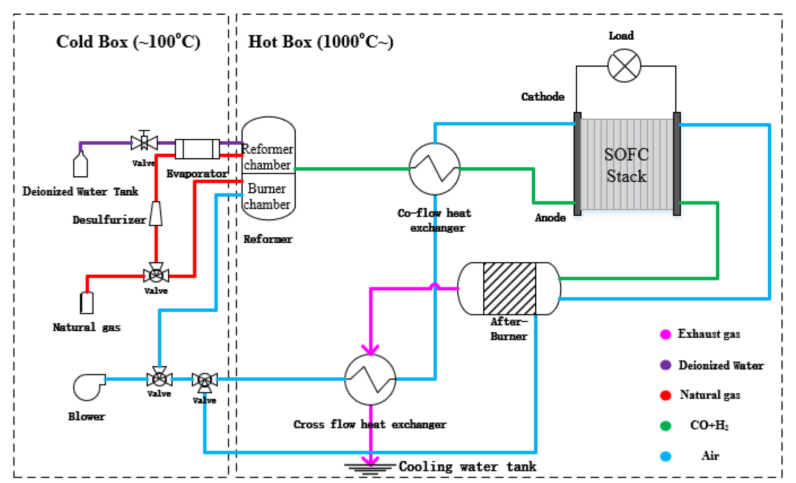

Figure 1. Architecture diagram of natural gas SOFC system.

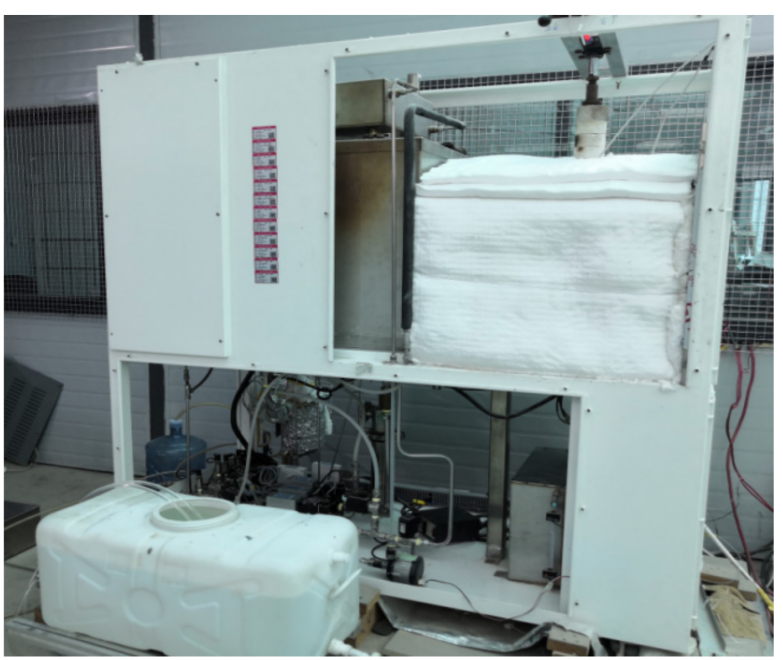

Figure 2. Physical diagram of SOFC system.

\subsection{The SOFC Stack Type}

This system key component is a planar type SOFC stack of $\mathrm{kW}$ class, which is consistent with the stack form of Yan [35]. The stack structure is shown in Figure 3. Specifically, the SOFC stack is an anode supported cross flow stack in the form of an outer airway. The anode support material of the cell is Ni-YSZ, and the thickness is $1 \mathrm{~mm}$. In the process of generation in SOFC stack, the internal of the stack generates steam, carbon dioxide, heat, and electric energy through an electrochemical reaction.

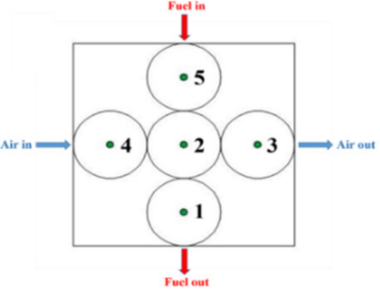

(a)

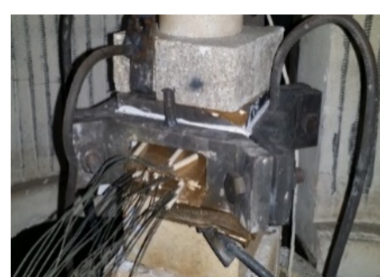

(b)

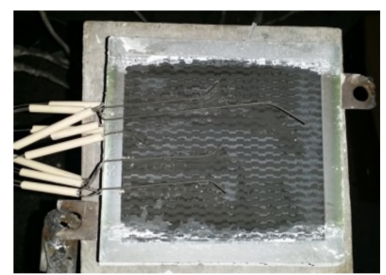

(c)

Figure 3. Structure of SOFC stack: (a) Stack cross-flow structure; (b) SOFC stack; (c) SOFC single cell.

\section{Multimode Modeling of SOFC System}

\subsection{System Multimode Divide Theory}

In the initial stage, the working conditions of SOFC system are the same. The transition period is gradually deepening with time. Until the transition stage, the dynamic characteristics of the system are similar to the next mode. Notably, the system operating characteristics 
during the transition period are not necessarily monotonous, but may fluctuate back and forth, during which other exceptional phenomena are more likely to occur:

$$
\left\{\begin{array}{c}
y_{1}=f_{1}\left(x_{1}, x_{2}, \ldots, x_{n}, u\right) \\
y_{2}=f_{2}\left(x_{1}, x_{2}, \ldots, x_{n}, u\right) \\
\vdots \\
y_{n}=f_{n}\left(x_{1}, x_{2}, \ldots, x_{n}, u\right)
\end{array}\right.
$$

In Equation (1), $x_{1}, x_{2}, \ldots, x_{n}$ are the state variables of the system, $y$ is the output of the system, $u$ is the input, and $f$ is the nonlinear relationship function between the input and output. In the system, the difference of state variables $x_{1}, x_{2}, \ldots, x_{n}$ can be used to divide the multimode. As far as each system mode is concerned, there are some differences in its state, which can be expressed by the system characteristic model $F=\left\{f_{1}, f_{2}, \ldots, f_{n}\right\}$.

Aiming at the multimode phenomenon of nonlinear system, it can be expressed in the form of phase plane. Here, the phase plane method uses the state variables $x_{1}$ and $x_{2}$ to divide the modes. Let $x_{1}=k, x_{2}=d k / d t, k$ is the deviation value. In the phase plane shown in Figure 4, the division threshold value regarded as the state feature $\alpha$ and $\beta$ is divided into six pieces. The division is based on the interval of the system feature model $F$, which is specifically expressed as:

$$
\left\{\begin{array}{c}
f_{1},\left\{-\alpha<x_{1}<0, x_{2}>-\beta\right\} \\
f_{2},\left\{0<x_{1}<\alpha, x_{2}<\beta\right\} \\
f_{3},\left\{-\alpha<x_{1}<0, x_{2}<-\beta\right\} \\
f_{4},\left\{0<x_{1}<\alpha, x_{2}>\beta\right\} \\
f_{5},\left\{x_{1}<-\alpha\right\} \\
f_{6},\left\{x_{1}>\alpha\right\}
\end{array}\right.
$$
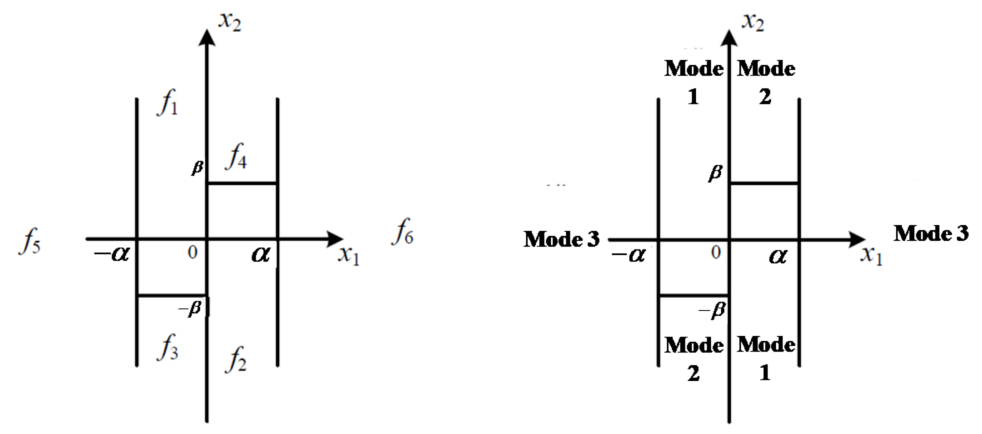

Figure 4. Multimode divide.

From the left figure in Figure 4 , the state characteristics of $f_{1}$ and $f_{2}$ are ideal, which can be regarded as a normal mode and classified as mode 1 (right figure in Figure 4), while the state characteristics of $f_{3}$ and $f_{4}$ are poor in error and far from the center of the phase plane diagram, which can be regarded as a transitional mode. Therefore, the state is classified as mode 2 (right figure in Figure 4). In terms of modal differences, the state characteristics of $f_{5}$ and $f_{6}$ are farthest from the center of the coordinate system. Therefore, they can be regarded as fault modes and classified into mode 3 (Figure 4 , right).

Moreover, there is a multimode division in SOFC system: When the system is in a different operation mode, the transition trajectory is different, and the working time is different. Due to the difference of stability under multimode conditions, if it cannot be analyzed qualitatively, it will affect the discrimination of SOFC system operation state. Therefore, it is necessary to model the SOFC system based on the mechanistic model and observe the SOFC system response trend. 


\subsection{SOFC System Modeling}

The SOFC system modeling in this section is based on the structure in Figure 1, which includes the reformer, stack, heat exchanger and afterburner, blower and pipeline, etc. Among them, the complex external factors and interference factors of the system itself are not considered in the modeling process. Therefore, the following assumptions are taken into consideration in the modeling process:

(1) In the process of gas supply, the lag phenomenon caused by the flowmeter, desulfurizer, and sensor is replaced by the first-order inertia delay link;

(2) Since the multimode modeling belongs to the SOFC system work level, it does not consider the internal factors of the stack, but only considers its temperature characteristics and electrical characteristics;

(3) The system monitoring elements, such as flowmeter, pressure sensor, and temperature sensor are disregarded;

(4) Neglecting the temperature gradient distribution in each subsystem of the system;

(5) All of the gases are ideal;

(6) The system has good thermal insulation and no heat exchange with the external environment;

(7) Each cell efficiency of SOFC stack is equal;

(8) The modeling method of strictly monotonic degradation with time is adopted for the fault transition stage.

According to the aforementioned assumption, it can effectively reduce the difficulty of SOFC system multimode modeling. At the same time, in order to observe the difference of multimode changes, the fault degradation coefficient should be increased appropriately in the fault mode modeling.

(1) SOFC stack model

The electric characteristic equation of SOFC is as follows:

$$
U_{\text {stack }}=n_{\text {cell }} \times U_{\text {cell }}=n \times\left(E^{0}+\frac{K T_{\text {cell }}}{2 F} \ln \left(\frac{P_{\mathrm{H}_{2}} P_{\mathrm{O}_{2}}^{0.5}}{P_{\mathrm{H}_{2} \mathrm{O}}}\right)\right)
$$

In Equation (2), cell is the number of cells, $U$ is voltage (V), $P$ is pressure (bar), $F$ is faraday constant, and $K$ is general gas constant.

The energy conservation equation of SOFC is shown in Equations (3) and (4):

$$
\begin{gathered}
\frac{d T_{\text {stack }, \text { out }}}{d t} C_{\text {stack }} V_{\text {stack }} \rho_{\text {stack }}=\dot{Q}_{\text {stack,in }}-\dot{Q}_{\text {stack,out }}-J A_{\text {stack }} U_{\text {stack }} \\
\dot{Q}_{\text {stack,in (out) })}=\sum_{i} \dot{N}_{i, \text { in (out })} h_{i, \text { in (out })} T_{\text {stack,in(out) }}
\end{gathered}
$$

where $i=\left[\mathrm{H}_{2} \mathrm{O}, \mathrm{H}_{2}, \mathrm{CH}_{4}, \mathrm{CO}_{2}, \mathrm{CO}, \mathrm{N}_{2}, \mathrm{O}_{2}\right], \mathrm{C}$ is the specific heat capacity $\left(\mathrm{J} /\left(\mathrm{kg}{ }^{\circ} \mathrm{C}\right)\right) \mathrm{V}$ is volume $\left(\mathrm{m}^{3}\right), \rho$ is density $\left(\mathrm{kg} \cdot \mathrm{m}^{3}\right), \dot{N}$ is flow rate $(\mathrm{mol} / \mathrm{s}), T$ is temperature $\left({ }^{\circ} \mathrm{C}\right), h$ is enthalpy $(\mathrm{J} / \mathrm{mol})$, and $\dot{Q}$ is energy value $(\mathrm{W})$.

In addition, the SOFC stack temperature is divided into five equal nodes based on the direction of gas flow, and the node modeling is completed according to the reference.

\section{(2) Reformer model}

In the system studied in this paper, the reformer type is steam reforming, and the heating mode is the combustion chamber ignition combustion, not the exhaust gas combustion chamber heating. Therefore, the combustion chamber temperature of the reformer is set at $650{ }^{\circ} \mathrm{C}$. For the modeling of the reforming chamber, Equations (5) and (6) can be used:

Energy conservation equation:

$$
\sum \dot{Q}_{\text {reformer, }, \text { in }}=\frac{d T}{d t} C_{\text {reformer }} V_{\text {reformer }} \rho_{\text {reformer }}
$$


The mass conservation equation is as follows:

$$
\frac{d \dot{N}_{i}}{d t}=\dot{N}_{i, \text { in }}^{f u e l}+\dot{N}_{i, \text { steam }}^{\text {steam }}-\dot{N}_{i, \text { out }}^{\text {fuel }}+\sum R_{\text {reformer }}
$$

In Equations (5) and (6), $R$ is the molar reaction rate. Using $R_{i}=\dot{N}_{i n} X_{i, \text { in }}$, the reaction rate of reformer is obtained. $X$ is the mole fraction of component $i$, and the meanings of the other parameters are consistent with Equations (3) and (4).

\section{(3) Afterburner}

For the afterburner, where there is a combustion reaction, the energy conservation equation is mainly described by Equation (7):

$$
\sum \dot{Q}_{a f t e r b u r n e r, i n}=\frac{d T}{d t} C_{\text {afterburner }} V_{\text {afterburner }} \rho_{\text {afterburner }}
$$

The mass conservation equation is as follows:

$$
\dot{N}_{\text {afterburner,out }}=\dot{N}_{\text {afterburner, in }}+\sum R_{\text {afterburner }}
$$

The meanings of the relevant parameters in Equations (7) and (8) are consistent with Equations (3) and (4).

\section{(4) Heat exchanger}

For the heat exchanger, there is only the heat exchange and no material change.

Energy conservation equation:

$$
\begin{gathered}
\sum \dot{Q}=U A \Delta T \\
\Delta T=f\left(\left(T_{\text {in }}^{\text {hot }}-T_{\text {out }}^{\text {cold }}\right),\left(T_{\text {out }}^{\text {hot }}-T_{\text {in }}^{\text {cold }}\right)\right)
\end{gathered}
$$

In Equations (9) and (10), it is the area and the change of temperature.

The mass conservation equation is as follows:

$$
\begin{gathered}
\dot{N}_{\text {in }}^{\text {hot }}=\dot{N}_{\text {out }}^{\text {hot }} \\
\dot{N}_{\text {in }}^{\text {cold }}=\dot{N}_{\text {out }}^{\text {cold }}
\end{gathered}
$$

Equations (11) and (12) reflect that the inlet and outlet gas flow rate of hot gas pipeline in the heat exchanger is equal, and the inlet and outlet gas flow rate of normal temperature gas pipeline is also equal.

The detailed modeling of the aforementioned subcomponents and other BOP components are completed by referring to the relevant general mechanistic equations. In addition, in order to deeply observe the evolution process of system performance, the system efficiency index is introduced to investigate the operation state of SOFC system in various modes:

$$
S E=\frac{n \times U \times I}{\dot{N}_{\mathrm{CH}_{4}} \times L H V_{\mathrm{CH}_{4}}} \times 100 \%
$$

where $S E$ is the system efficiency considering only the electrical characteristics, $n$ is the number of cells, $U$ is the voltage value, $I$ is the current value of the system discharge, $\dot{N}_{\mathrm{CH}_{4}}$ is the flow rate of the fuel used for hydrogen production and heat supply by reforming, and $\mathrm{LHV}_{\mathrm{CH}_{4}}$ is the low calorific value of methane. 


\subsection{Multimode Modeling of SOFC System}

The normal state modeling method has been described as previously mentioned. This section mainly introduces the modeling of SOFC system fault and transition states based on the typical fault types and related transition states that may occur in each key unit of the system.

\section{(1) Rupture of heat exchanger}

The fault is the air pipeline rupture in the heat exchanger, where the exhaust gas from the afterburner exchanges heat with cold air at normal temperature. The main causes of this fault are excessive air supply pressure and afterburner high temperature.

In order to simulate the fault, the mechanistic equation of releasing air at the hole should be added to the heat exchanger model. Starting from the heat exchanger pipeline in Figure 5, in this scheme, the gas flow rate participating in the heat exchange per unit time is obtained by simulating the loss of gas flow rate. The relevant mechanistic equations are shown in Equations (14) and (15):

$$
\begin{aligned}
& \dot{N}_{2, \text { in }}=\dot{N}_{1, \text { out }}-\dot{N}_{H} \\
& \dot{N}_{H}=\dot{N}_{1, \text { out }}(1-\omega)
\end{aligned}
$$

where $\dot{N}_{H}$ is the air flow rate at the outlet of the hole. The gas flow rate known to leak can be obtained by Equation (14) to obtain the air flow rate participating in the system.

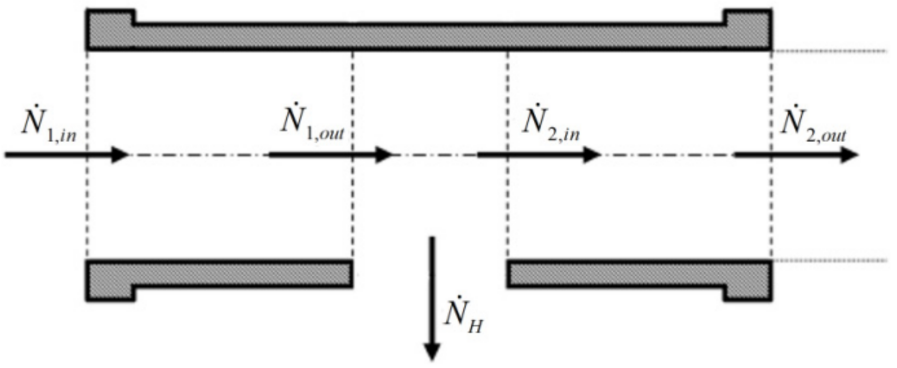

Figure 5. Gas leakage of heat exchanger.

\section{(2) Performance degradation of reformer}

The performance degradation of the pre-reformer is a typical fault. This fault is mainly caused by carbon deposition in the reformer. Specifically, carbon deposition affects the reaction degree of fuel and deionized water under the action of catalyst, which changes the production of $\mathrm{CO}$ and $\mathrm{H}_{2}$ per unit time. In order to simulate this fault, the area of reforming reaction zone $A_{r e f}$ is reduced according to Equation (16):

$$
A_{\text {reformer }, m}=A_{\text {reformer }}(1-\chi)
$$

where the coefficient $\chi$ is limited in the range of $[0,1]$, which is related to the fault degree. In addition, the reformer fault will also affect the change of outlet fuel temperature.

\section{(3) Imbalance of gas flow in afterburner}

In the SOFC system, the imbalance of gas flow in the afterburner is usually caused by the electrochemical reaction instability of the front-end components, rather than the structural damage of the afterburner itself. This is due to the fact that in the SOFC system, the system peak temperature is in the afterburner, and its temperature is stably distributed in the hot areas of the system through the pipeline, heat exchanger, and other components, supplemented by gas flow. Therefore, the afterburner has enough high temperature resistance and stability when it does not exceed the limited ignition point of its material. Most of the problems in the afterburner are caused by the change of the external input gas properties, which affects the internal combustion characteristics. In order to simulate 
the gas flow imbalance in the afterburner, the change Equation (17) of gas flow rate in the afterburner is used to express the fault:

$$
\dot{N}_{\text {burner,in }}=\dot{N}(1+\kappa)
$$

where $\kappa$ is the coefficient of variation in the range of $[-1,1]$, which reflects the increase or decrease of the afterburner inlet gas flow rate. If $\kappa$ is a positive value, it indicates that the gas flow rate increases at the inlet of the afterburner, otherwise it decreases.

(4) Degradation of stack electrical characteristics

The increase of SOFC stack ohmic resistance will result in the decrease of stack voltage under constant current. Therefore, according to Equation (18), the fault is introduced in the stack voltage model:

$$
U_{\text {stack, } m}=U_{\text {stack }}(1-\varepsilon)
$$

where $\varepsilon$ is the coefficient varying in the range of $[0,1]$ and is related to the fault amplitude.

(5) Modeling of transition modes

Transition mode is the transition state between the normal and fault modes of SOFC system. There is a process from quantitative change to qualitative change in the process of mode change. Therefore, the modeling of transition mode is the same as the fault mode, and only the degradation coefficient is modified. Table 2 shows the specific transition mode degradation coefficient and fault mode degradation coefficient.

Table 2. Transition and fault mode degradation coefficient for SOFC system typical faults.

\begin{tabular}{ccc}
\hline Fault Type & Transition Mode & Fault Mode \\
\hline Rupture of heat exchanger & 0.05 & 0.3 \\
Performance degradation of reformer & 0.05 & 0.3 \\
Imbalance of gas flow in afterburner & 0.3 & 0.5 \\
Stack performance degradation & 0.05 & 0.3 \\
\hline
\end{tabular}

\subsection{Model Verification}

In order to verify the accuracy of modeling, the instruments shown in Table 3 are used to detect the thermoelectric characteristics of the stack. The electronic load is used to detect the SOFC system electrical parameters from the experiment, and the temperature is measured by the platinum rhodium thermocouple.

Table 3. Instruments used for model validation.

\begin{tabular}{cccc}
\hline Sensors & Instrument & Accuracy & Rangeability \\
\hline Temperature & Pt-Rh Thermocouple & $1{ }^{\circ} \mathrm{C}$ & $0-1600{ }^{\circ} \mathrm{C}$ \\
Voltage & Electronic load & $0.001 \mathrm{~V}$ & $0-500 \mathrm{~V}$ \\
Power & Electronic load & $0.001 \mathrm{~W}$ & $0-2.4 \mathrm{~kW}$ \\
Current & Electronic load & $0.1 \mathrm{~A}$ & $0-120 \mathrm{~A}$ \\
\hline
\end{tabular}

The experiments are used to test the stack modeling effect. The experimental conditions are as follows: The choice of fuel and air flow rate is consistent with the model. Before entering the stack, the fuel will be preheated in the electric furnace to be close to the stack temperature. The air is preheated to approximately $600{ }^{\circ} \mathrm{C}$. The currents measured experimentally and calculated by the model are compared in Table 4. Evidently, when a single cell voltage is $0.6 \mathrm{~V}$ higher than its safety voltage, the current matching is good. The $I_{\text {exp }}$ is the experimental voltage, and $I_{\text {model }}$ is the model voltage. 
Table 4. Experimental voltage and model voltage under different current conditions.

\begin{tabular}{cccccc}
\hline Voltage & $\mathbf{0 ~ V}$ & $\mathbf{0 . 4} \mathbf{~ V}$ & $\mathbf{0 . 6} \mathbf{~}$ & $\mathbf{0 . 8 ~ V}$ & $\mathbf{1 ~ V}$ \\
\hline$I_{\exp }$ & $0 \mathrm{~A}$ & $16 \mathrm{~A}$ & $23 \mathrm{~A}$ & $21 \mathrm{~A}$ & $5 \mathrm{~A}$ \\
$I_{\text {model }}$ & $0 \mathrm{~A}$ & $17.7 \mathrm{~A}$ & $23.2 \mathrm{~A}$ & $21.3 \mathrm{~A}$ & $5.1 \mathrm{~A}$ \\
\hline
\end{tabular}

In terms of temperature, the differences between the experiment and the model are compared in Figure 6. It can be seen that the model and experimental results show a rising trend of temperature from the cross-current stack inlet and outlet direction. In this way, it can be proved that the experimental qualitative analysis can be carried out on the built model.

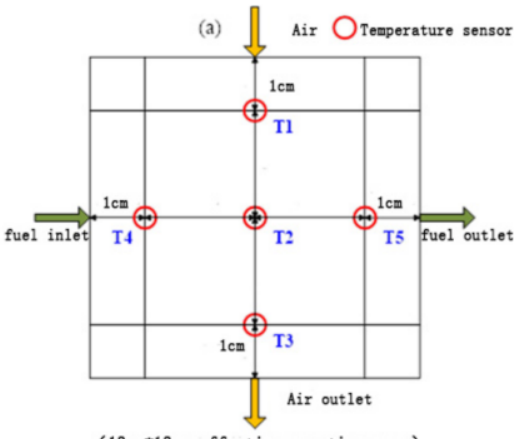

$(13 \mathrm{~cm} * 13 \mathrm{~cm}$ effective reaction area)

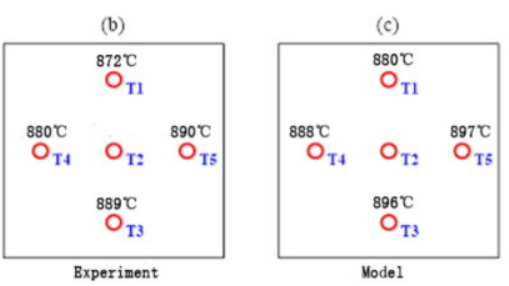

Figure 6. Model temperature verification of cross-flow SOFC stack: (a) Stack temperature sensor location; (b) Temperature distribution of SOFC stack in experiment; (c) Temperature distribution of SOFC stack in the model.

In addition, the temperature difference is due to the fact that the temperature is measured by connecting the temperature sensor (thermocouple) with the SOFC stack outer wall, in order to maintain the SOFC stack tightness. For the voltage, the wire loses a little voltage, and thus the modeling error is reasonable. Therefore, the aforementioned model can be used to qualitatively analyze the thermoelectric operation trend of the system.

\section{Results and Discussion}

\subsection{Normal Mode Dynamic Analysis}

Based on the aforementioned model description, the SOFC system model as shown in Figure 7 is built according to Figure 1. Then, the system parameters are set which can operate stably. In this case, the operation result is regarded as the normal working condition of SOFC system. At the same time, in order to more significantly represent the dynamic response characteristics of the system, a larger value is selected as the system operation parameters, and the set specific parameters are shown in Table 5.

Based on the aforementioned parameters, the total running time of the model is set to $150,000 \mathrm{~s}$. In addition, the main performance output results of SOFC system are obtained in normal mode. The trend chart is shown in Figure 8. The stack temperature is subject to the stack last node temperature. 


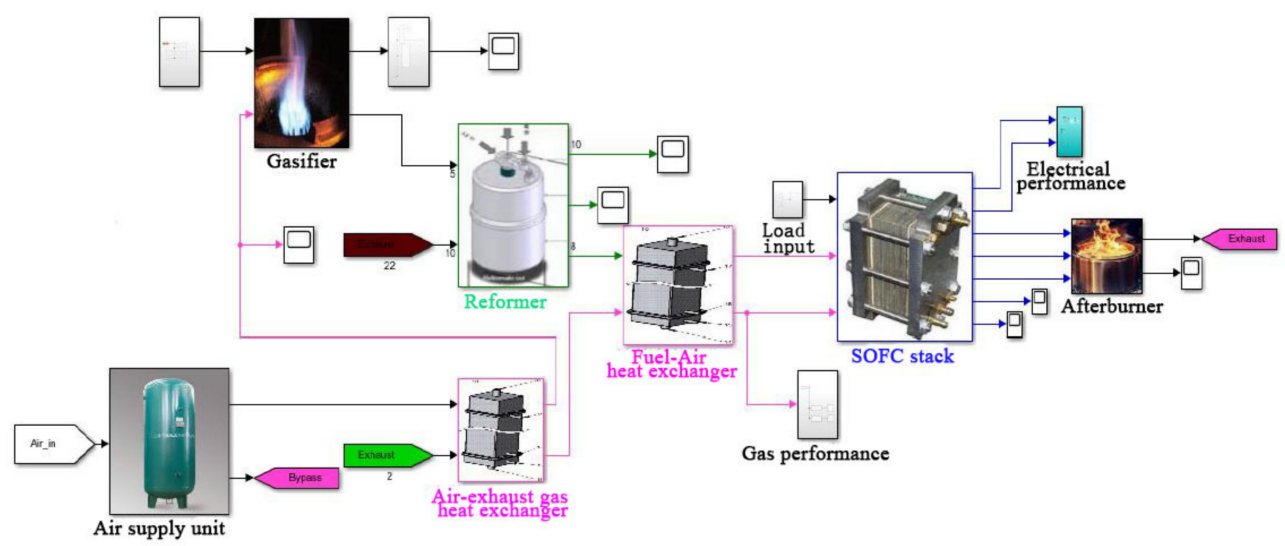

Figure 7. SOFC system model structure.

Table 5. SOFC system main parameters.

\begin{tabular}{cccc}
\hline Stack Parameter & Set Value & Input Variables & Set Value \\
\hline Number of Cell & 27 cells & Single cell voltage & $0.76 \mathrm{~V}$ \\
Cell width & $0.15 \mathrm{~m}$ & Steam to carbon ratio & 2.8 \\
Cell length & $0.15 \mathrm{~m}$ & Fuel supply pressure & $3.5 \mathrm{Bar}$ \\
PEN layer thickness & $5 \times 10^{-4} \mathrm{~m}$ & Deionized water supply & $0.02 \mathrm{~mol} / \mathrm{s}$ \\
Effective reaction area & $169 \mathrm{~cm}^{2}$ & Heating temperature of reformer & $650^{\circ} \mathrm{C}$ \\
PEN specific heat capacity & $0.5 \mathrm{~kJ} \mathrm{~kg}^{-1} \mathrm{~K}^{-1}$ & State of bypass valve & Off \\
\hline
\end{tabular}

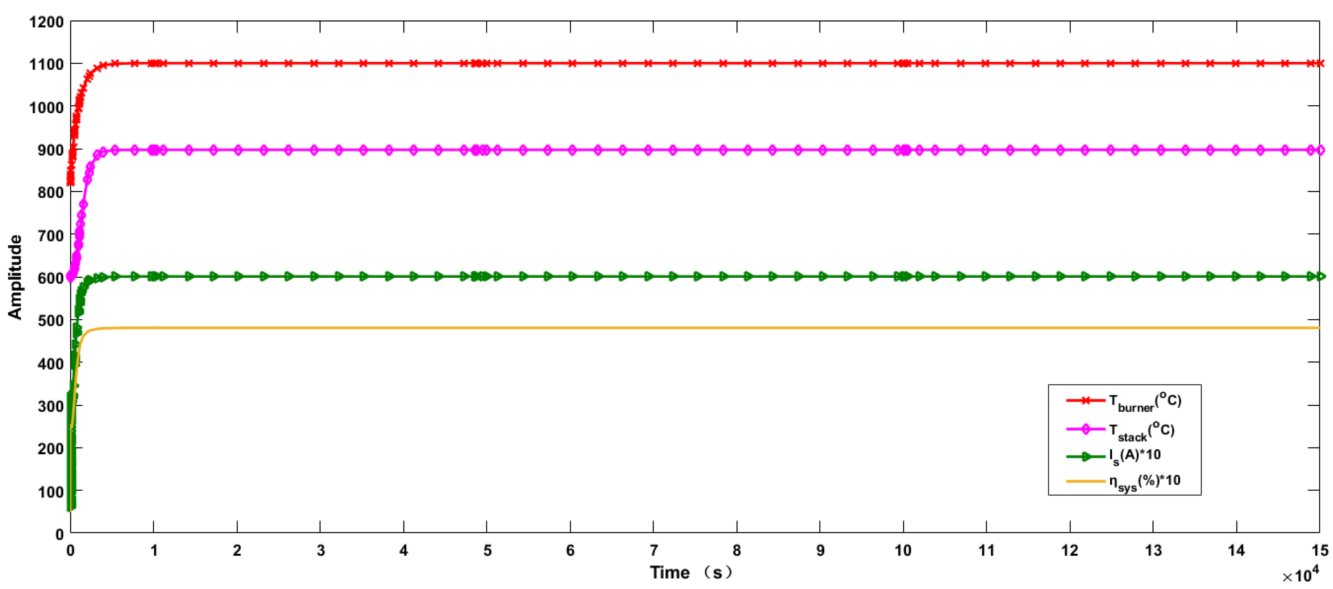

Figure 8. SOFC system main performance parameters under normal condition.

In Figure 8, the system tends to be stable in normal mode after the initial stage of about $10,000 \mathrm{~s}$. The afterburner temperature reaches $1100^{\circ} \mathrm{C}$ (red line) after entering the steady state, and the stack temperature reaches $897^{\circ} \mathrm{C}$ (pink line) after entering the steady state. For the convenience of observation in Figure 8, the actual value of current is magnified 10 times in the figure, and the actual current is about $60 \mathrm{~A}$ (green line). In addition, the system efficiency in the figure is magnified 10 times, and the actual system efficiency is about $48 \%$ (yellow line). Table 6 presents the temperature of five nodes of the SOFC stack, and the differences are evidently in a reasonable range, meeting the safe requirement temperature gradient.

After obtaining the normal operation results of SOFC system, in order to compare the system response characteristics under the fault and transition modes, it is necessary to introduce the transition and fault modes to observe the system performance change trend. Therefore, the introducing time of transition mode is set to 50,000 s, and the introducing time of fault mode is set to $100,000 \mathrm{~s}$. 
Table 6. Temperature distribution of SOFC stack nodes in normal condition.

\begin{tabular}{cccccc}
\hline Temperature & Node $\mathbf{1}$ & Node 2 & Node 3 & Node 4 & Node 5 \\
\hline Anode & 888 & 893 & 896 & 892 & 897 \\
PEN & 889 & 894 & 897 & 892 & 897 \\
Cathode & 880 & 892 & 896 & 892 & 896 \\
Interconnect & 888 & 893 & 896 & 892 & 896 \\
\hline
\end{tabular}

\subsection{Rupture of Heat Exchanger}

Substituting Equations (14) and (15) into the system model, and substituting the degradation coefficient shown in Table 2, the transition and fault mode response curves of the heat exchanger rupture are obtained as shown in Figure 9.

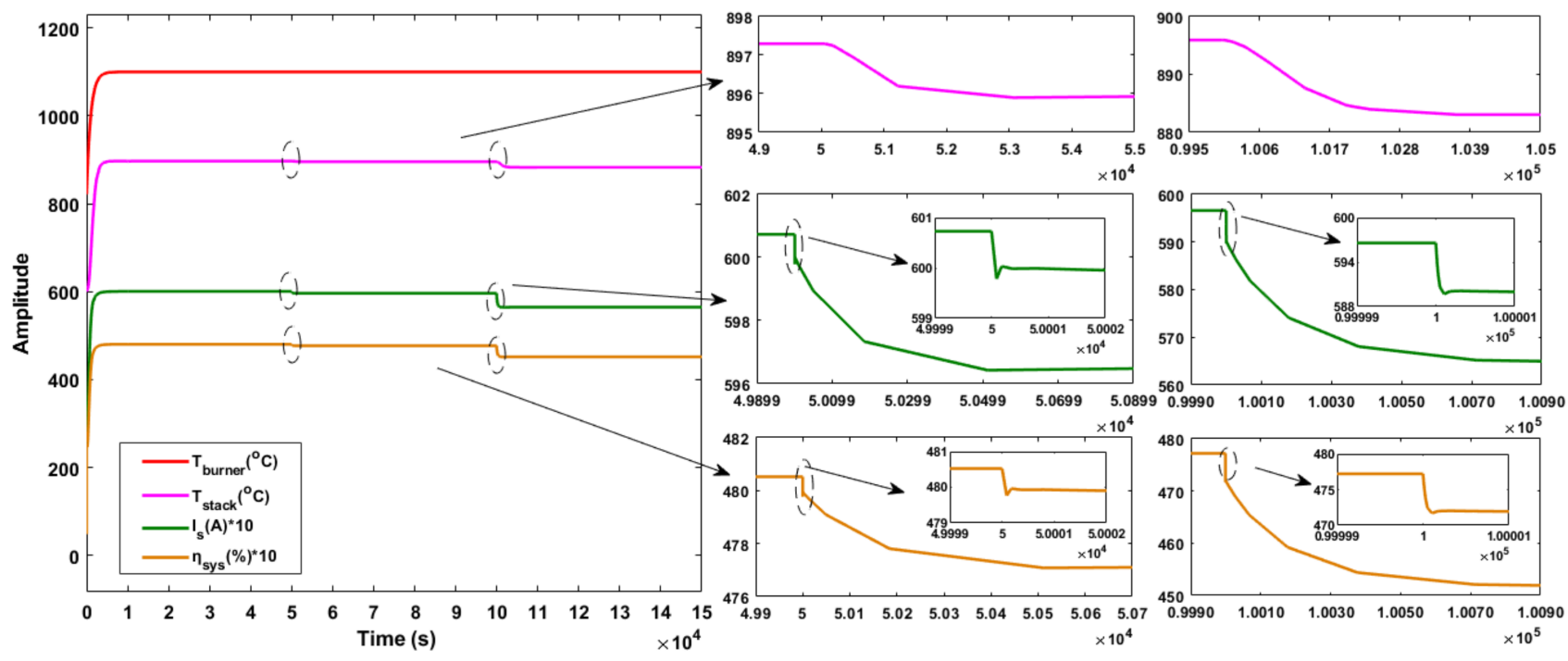

Figure 9. The performance curve of system mode change is caused by the heat exchanger fault.

Based on the results in Figure 9, when the system enters into a steady-state operation in about $10,000 \mathrm{~s}$, the afterburner temperature is stable at $1100{ }^{\circ} \mathrm{C}$, and the stack temperature is stable at $897^{\circ} \mathrm{C}$, when the stack operates at a constant voltage of $27 \times 0.76=20.52 \mathrm{~V}$, the current is stable at $60.01 \mathrm{~A}$, and the system efficiency is $48 \%$. When the system runs to $50,000 \mathrm{~s}$, the system enters the transition mode before the heat exchanger fault. Thereafter, the afterburner temperature does not change evidently, while the temperature, the SOFC stack discharge current, and the system efficiency decrease slightly. However, the system immediately enters a new steady state after a short period of self-regulation. In the transition mode, the SOFC stack discharge current is about $59.6 \mathrm{~A}$, which is only 0.4 A lower than the normal state, while the system operation efficiency returns to the new steady state rapidly after the sudden drop, and then the operation efficiency is stable at $47.7 \%$ in the transition mode.

When the system runs to $100,000 \mathrm{~s}$, the fault mode is introduced into the system, and both the system efficiency and the stack discharge current are significantly reduced. After a short adjustment, the system efficiency is reduced to $47.2 \%$ and the stack discharge current is reduced to 59 A. According to Table 7, the stack temperature distribution in transition and fault modes do not exceed the safety range.

The mode change of SOFC system caused by the heat exchanger fault has no significant effect during the transition mode. However, the system efficiency and stack discharge current are significantly reduced during the fault mode. For the temperature of the stack and afterburner, the rupture of the heat exchanger only leads to the reduction of the air flow rate in the system cathode pipeline, which can only show the slight decrease of electrochemical reaction degree in the SOFC stack. Under the condition of constant fuel 
supply, the slight decrease of electrochemical reaction degree will only make the stack gas contain more combustible substances. After these combustibles flow into the afterburner, the combustion in the afterburner cannot be fully carried out due to the lack of air supply. This is the reason that although the combustibles quality of afterburner has been improved, the afterburner temperature has not changed.

Table 7. Temperature distribution of SOFC stack nodes due to the heat exchanger fault.

\begin{tabular}{ccccccccccc}
\hline \multirow{2}{*}{ Temperature } & \multicolumn{4}{c}{ Transition Mode of Heat Exchanger } & \multicolumn{4}{c}{ Fault Mode of Heat Exchanger } \\
\cline { 2 - 11 } & Node 1 & Node 2 & Node 3 & Node 4 & Node 5 & Node 1 & Node 2 & Node 3 & Node 4 & Node 5 \\
\hline Anode & 887 & 892 & 895 & 890 & 895 & 874 & 879 & 882 & 878 & 882 \\
PEN & 887 & 893 & 896 & 890 & 896 & 874 & 880 & 883 & 878 & 883 \\
Cathode & 878 & 891 & 895 & 891 & 895 & 863 & 878 & 882 & 878 & 882 \\
Interconnect & 886 & 892 & 895 & 891 & 895 & 873 & 879 & 882 & 878 & 882 \\
\hline
\end{tabular}

In addition, although there is an exothermic reaction inside the stack, due to the lack of air supply, the electrochemical reaction degree inside the stack is reduced and the heat released inside the stack is reduced. At the same time, due to the rupture of the heat exchanger, the ability of heat exchange between the high-temperature exhaust gas from the afterburner and the cathode air is significantly reduced, which causes the lower air temperature to flow into the stack cathode. Therefore, when the heat exchanger breaks, the stack temperature decreases in varying degrees.

\subsection{Reformer Performance Degradation}

In order to obtain the key parameter curve of SOFC system performance change under the reformer fault, Equation (16) is substituted into the system model, and the degradation coefficient shown in Table 2 is substituted into the system model. The transition and fault mode response curves of the obtained reformer performance degradation are shown in Figure 10.
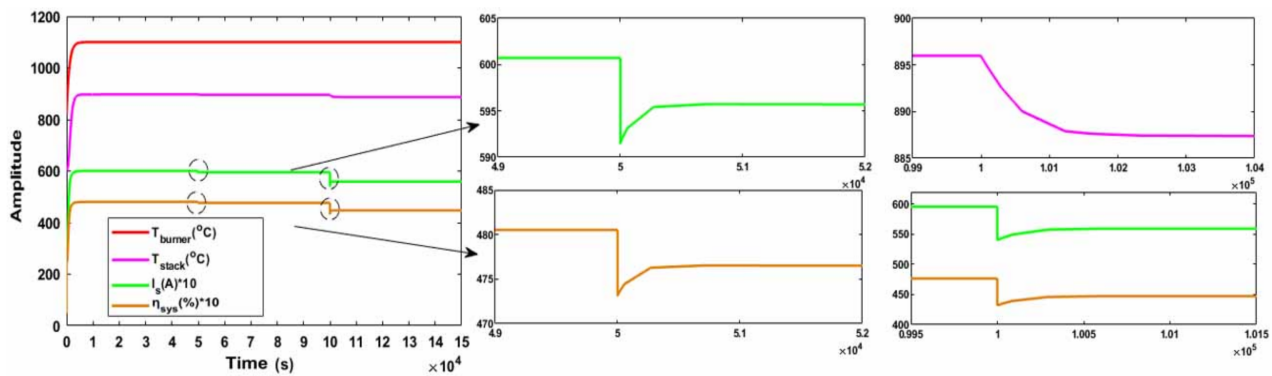

Figure 10. The performance parameter curve of system mode change caused by the reformer fault.

From the results in Figure 10, when the system enters the steady-state operation in about 10,000 s, the key performance parameters are consistent with the situation when the system is in normal mode before entering the transition mode. After a period of time, when the system runs to 50,000 s, the afterburner temperature does not change significantly after introducing the transition mode, while the SOFC stack temperature, discharge current, and the system efficiency decrease slightly. Similarly, the system enters a new steady-state operation after a short period of self-regulation. In the transition mode, the SOFC stack discharge current is about $59.1 \mathrm{~A}$, and then it rises to $59.6 \mathrm{~A}$, which is only $1 \mathrm{~A}$ lower than the normal mode. Moreover, the system efficiency rises to a new steady state after a sudden drop, and the system efficiency has been stable at $47.6 \%$ in the transition mode.

When the system runs to $100,000 \mathrm{~s}$, the fault mode is introduced into the system, and both the system efficiency and the stack discharge current are significantly reduced. After a short adjustment, the system efficiency is reduced to $44.7 \%$ and the stack discharge current is reduced to $55.9 \mathrm{~A}$, which is $3.2 \mathrm{~A}$ lower than the transition mode. The temperature 
distribution of SOFC stack nodes is shown in Table 8, in which the temperature gradient of SOFC stack meets thermal safety requirements.

Table 8. Temperature distribution of SOFC stack nodes due to the reformer fault.

\begin{tabular}{ccccccccccc}
\hline \multirow{2}{*}{ Temperature } & \multicolumn{4}{c}{ Transition Mode of Reformer } & \multicolumn{4}{c}{ Fault Mode of Reformer } \\
\cline { 2 - 11 } & Node 1 & Node 2 & Node 3 & Node 4 & Node 5 & Node 1 & Node 2 & Node 3 & Node 4 & Node 5 \\
\hline Anode & 888 & 892 & 895 & 890 & 895 & 886 & 887 & 888 & 883 & 887 \\
PEN & 888 & 893 & 896 & 890 & 896 & 886 & 888 & 889 & 883 & 887 \\
Cathode & 880 & 891 & 895 & 891 & 895 & 879 & 887 & 888 & 884 & 887 \\
Interconnect & 887 & 892 & 895 & 891 & 895 & 885 & 887 & 888 & 883 & 887 \\
\hline
\end{tabular}

The mode change of SOFC system caused by the reformer fault has a significant impact on the system efficiency, stack temperature, and stack discharge current in transition, and the impact is further deepened during the fault mode. The stack temperature, discharge current, and system efficiency are significantly reduced in Figure 10. For the stack and afterburner temperature, the reformer fault only leads to a slight decrease of reformed fuel composition and temperature (since the reforming reaction is endothermic), and more methane will enter the stack. It will cause a small amount of carbon deposition in the reformer, pipeline or stack, resulting in the reduction of electrochemical reaction degree, which increases fuel in the afterburner. Due to the fact that when the fuel remains unchanged, one part of the fuel is lost due to carbon deposition and the other part is consumed by an electrochemical reaction, this reduces the heat of the afterburner and the heat released by the stack. Although combustible materials increase in the afterburner, the trace amount of combustible materials is not enough to increase the afterburner temperature, which is the reason that the afterburner temperature has not changed significantly.

In addition, although the exothermic reaction takes place inside the stack, the fuel reduction decreases the electrochemical reaction degree, which also reduces the heat released inside the stack. At the same time, sufficient supply of cathode air generates lower heat in the stack, and the stack temperature is reduced. From the stack temperature distribution data shown in Table 8, when the reformer performance degrades, each node temperature of SOFC stack decreases compared with the normal mode.

\subsection{Gas Flow Imbalance in Afterburner}

In order to observe the SOFC system fault performance caused by the gas flow imbalance in the afterburner, Equation (17) is substituted into the system model, and the degradation coefficient of Table 2 is substituted into the system model. The transition and fault mode response curves of afterburner gas flow imbalance are shown in Figure 11.
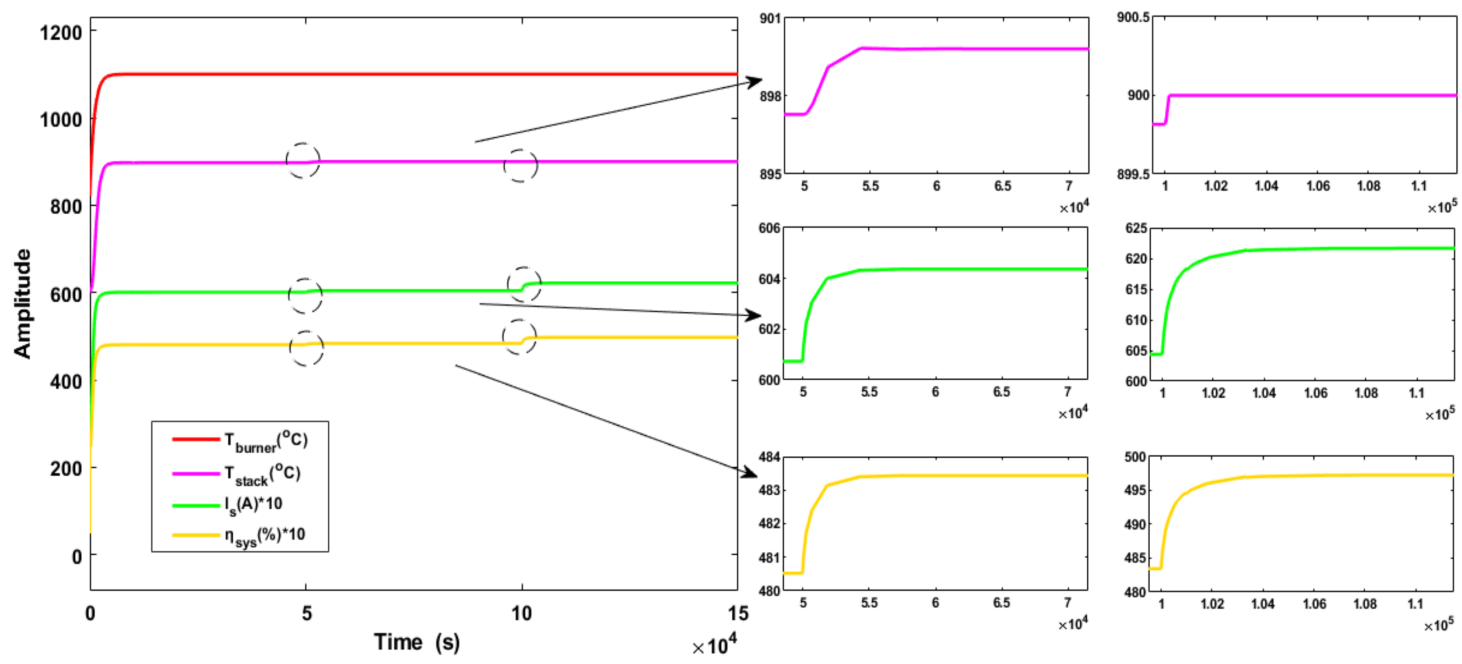

Figure 11. The system performance parameter curve caused by the imbalance of afterburner inlet air flow. 
In Figure 10, when the system enters a steady-state operation in about 10,000 s, the key performance parameters are consistent with the global normal mode before the system enters the transition mode. After a period of time, when the system runs to 50,000 s, the afterburner and SOFC stack temperature do not change significantly (the temperature change is about $3^{\circ} \mathrm{C}$ ), the SOFC stack discharge current and the system efficiency only slightly increase after the air flow rate increases, and the system efficiency increases from $48 \%$ to about $48.35 \%$, which can be ignored. In transition mode, the SOFC stack discharge current is about $60.4 \mathrm{~A}$, which is only $0.3 \mathrm{~A}$ higher than the normal mode. However, the system efficiency quickly rises to a new steady state, and the system efficiency is stable at $48.35 \%$ in the transition mode.

When the system runs to $100,000 \mathrm{~s}$, the gas flow imbalance fault mode of the afterburner is introduced into the system. Both the system efficiency and the stack discharge current are consistent with the transition mode. After a small increase, the system remains stable. The current is stable at about $62 \mathrm{~A}$, and the system efficiency is about $49.6 \%$. There is almost no change in the stack and afterburner temperature. In the two modes, the SOFC stack node temperature distribution is shown in Table 9. The imbalance of afterburner air flow does not lead to a significant increase in the stack node temperature. Therefore, the stack temperature gradient is in a safe range.

Table 9. Temperature distribution of SOFC stack nodes caused by the afterburner gas imbalance.

\begin{tabular}{|c|c|c|c|c|c|c|c|c|c|c|}
\hline \multirow{2}{*}{ Temperature } & \multicolumn{5}{|c|}{ Transition Mode of Afterburner Gas Flow Imbalance } & \multicolumn{5}{|c|}{ Fault Mode of Afterburner Gas Flow Imbalance } \\
\hline & Node 1 & Node 2 & Node 3 & Node 4 & Node 5 & Node 1 & Node 2 & Node 3 & Node 4 & Node 5 \\
\hline Anode & 891 & 896 & 899 & 894 & 899 & 900 & 899 & 899 & 895 & 899 \\
\hline PEN & 891 & 896 & 899 & 894 & 900 & 900 & 900 & 900 & 895 & 900 \\
\hline Cathode & 883 & 894 & 898 & 895 & 899 & 892 & 899 & 900 & 896 & 899 \\
\hline Interconnect & 890 & 896 & 898 & 894 & 899 & 899 & 899 & 899 & 896 & 899 \\
\hline
\end{tabular}

The system mode caused by the afterburner imbalance fault has no significant effect during the transition and fault modes, but only has a small increase in system efficiency and stack discharge current. For the temperature of stack and afterburner, the influence is very small and can be disregarded. The main reason is that the afterburner has enough high temperature resistance, which is not enough to make the system component temperature change significantly.

\subsection{Performance Degradation of SOFC Stack}

In order to obtain the key parameter curve of SOFC system performance change under the SOFC stack performance degradation fault, Equation (18) is substituted into the system model, and the degradation coefficient shown in Table 2 is substituted into the system model. The transition and fault mode response curves of SOFC stack performance degradation are shown in Figure 12.

In Figure 12, when the system enters the steady-state operation in about 10,000 s, the key performance parameters are consistent with the normal mode before entering the transition mode. After a period of time, when the system runs to 50,000 s, the temperature of afterburner and SOFC stack does not change significantly (the temperature change is less than $0.1^{\circ} \mathrm{C}$ ) after introducing the transition mode of stack electrical characteristics degradation. While the SOFC stack discharge current and the system efficiency have a large degree of sudden drop, and the SOFC stack operates with a new steady state after the sudden drop. In the transition mode, the SOFC stack discharge current is about $57 \mathrm{~A}$, which is only 3 A lower than the normal state. In addition, the system efficiency reaches a new steady state rapidly, and the system efficiency is stabled at $46 \%$ in transition mode.

When the system runs to $100,000 \mathrm{~s}$, the stack fault mode is introduced into the system. Both the system efficiency and the stack discharge current decrease significantly, the system efficiency quickly stabilizes to $30 \%$, and the discharge current decreases to $37.6 \mathrm{~A}$ and remains stable. In the two modes, the SOFC stack node temperature distribution is shown 
in Table 10. The stack performance degradation leads to the large fluctuation of stack node temperature, which is dangerous for the SOFC stack temperature safety. Therefore, the stack temperature gradient has a significant potential safety hazard.
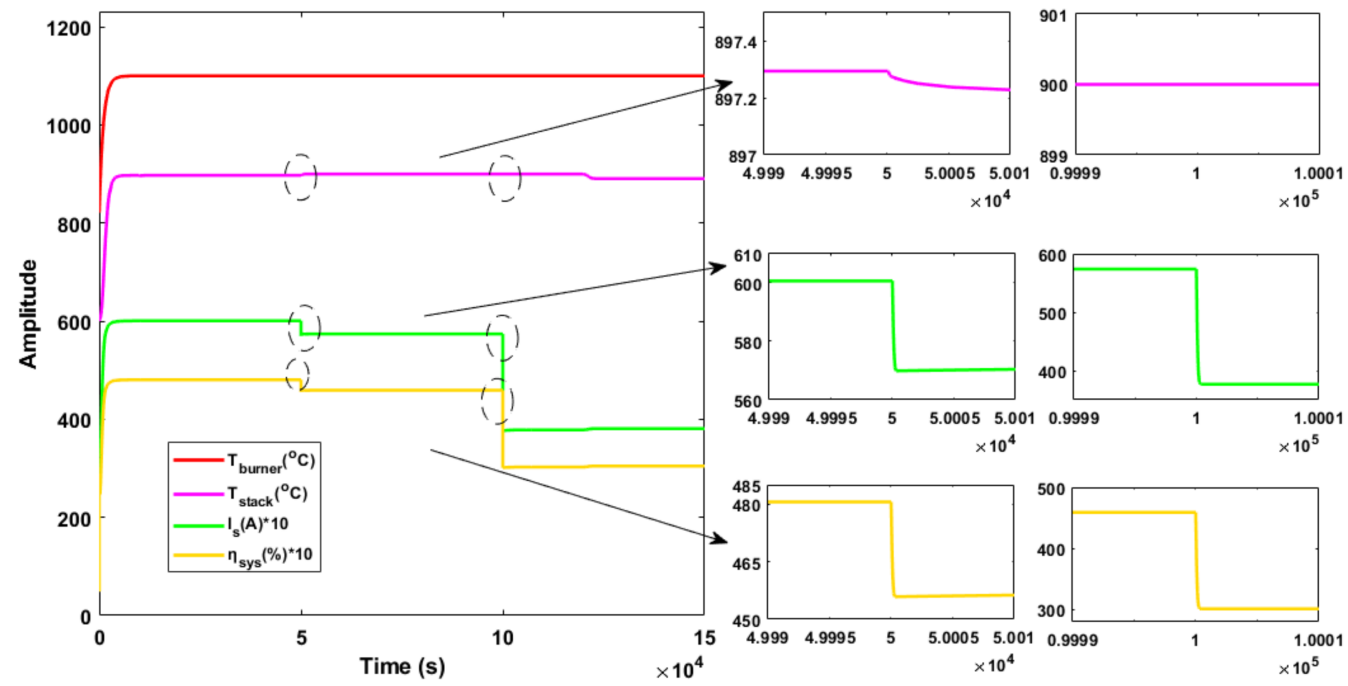

Figure 12. The performance parameter curve of system mode change caused by SOFC stack fault.

Table 10. Temperature distribution of stack nodes due to SOFC stack performance degradation.

\begin{tabular}{|c|c|c|c|c|c|c|c|c|c|c|}
\hline \multirow{2}{*}{ Temperature } & \multicolumn{5}{|c|}{ Transition Mode of Stack Performance Degradation } & \multicolumn{5}{|c|}{ Fault Mode of Stack Performance Degradation } \\
\hline & Node 1 & Node 2 & Node 3 & Node 4 & Node 5 & Node 1 & Node 2 & Node 3 & Node 4 & Node 5 \\
\hline Anode & 903 & 899 & 899 & 895 & 899 & 923 & 893 & 899 & 896 & 899 \\
\hline PEN & 900 & 900 & 900 & 895 & 900 & 900 & 893 & 900 & 896 & 900 \\
\hline Cathode & 886 & 898 & 899 & 896 & 899 & 847 & 887 & 898 & 896 & 899 \\
\hline Interconnect & 900 & 899 & 899 & 895 & 899 & 900 & 892 & 899 & 896 & 899 \\
\hline
\end{tabular}

The mode change of SOFC system caused by the stack fault has a significant impact on the stack temperature distribution, discharge current, and system efficiency. For the temperature of stack and afterburner, the stack electrical characteristics decrease the electrochemical reaction ability and stack temperature (the decrease is negligible since the decrease is less than $0.1^{\circ} \mathrm{C}$ ). Under constant fuel supply, there will only be more combustible materials flowing out of the stack. After these combustible materials flow into the afterburner, since the combustible materials are not large enough, the afterburner temperature cannot be effectively improved after full combustion. This causes the combustible materials in the afterburner to increase, but the afterburner temperature does not increase.

In addition, although there is an exothermic reaction inside the stack, the stack internal loss leads to the decrease of the electrochemical reaction degree, and the decrease of the heat released inside the stack, which is one of the reasons for the stack temperature to drop slightly. According to Table 10, the temperature of some stack nodes has increased, which is due to the stack internal structure changes. In Figure 12, the sudden drop of stack discharge current indicates that the SOFC stack fault cannot meet the discharge demand, which indirectly indicates the rationality of stack temperature drop.

\section{Conclusions}

The multimode model of SOFC system built in this paper qualitatively analyzes the thermoelectric characteristics of four typical fault working conditions. Based on the assumption of different typical fault modes, the fault modes of stack electrical characteristic degradation, reformer carbon deposition, afterburner gas flow imbalance, and heat exchanger rupture are defined and modeled. After the experimentally verified model runs for $50,000 \mathrm{~s}$, the transition mode of system fault is introduced, and the fault mode is introduced after $100,000 \mathrm{~s}$. The results show that the temperature characteristics of the four 
faults do not change very significantly from normal mode to fault mode, but the electrical characteristics (stack current and system efficiency) change most significantly. In particular, the system performance degrades evidently after the performance degradation of the stack. The impact of reformer and heat exchanger fault is relatively weak.

Although this paper uses the mechanistic model to study the multimode switching of SOFC system from a qualitative point of view, in order to more accurately reflect the relationship between the fault and input/output signals, the next step is to study the quantitative relationship of system multimode by combining data-driven experiments.

Author Contributions: Conceptualization, writing - original draft preparation and methodology, X.-L.W.; software, visualization, and validation, H.Z. and Y.-W.X.; formal analysis, H.L. and Y.W.; data curation and investigation, J.P. and Z.X.; resources, supervision, funding acquisition, and project administration, X.-L.W.; writing-review and editing, H.Z. All authors have read and agreed to the published version of the manuscript.

Funding: This research was funded by Jiangxi Provincial Natural Science Foundation, grant number 20212BAB212013.

Conflicts of Interest: The authors declare no conflict of interest.

\section{References}

1. Shah, A.V.; Srivastava, V.K.; Mohanty, S.S.; Varjani, S. Municipal solid waste as a sustainable resource for energy production: State-of-the-art review. J. Environ. Chem. Eng. 2021, 9, 105717. [CrossRef]

2. Foster, W.; Azimov, U.; Gauthier-Maradei, P.; Molano, L.C.; Combrinck, M.; Munoz, J.; Esteves, J.J.; Patino, L. Waste-to-energy conversion technologies in the UK: Processes and barriers-A review. Renew. Sustain. Energy Rev. 2021, 135, 110226. [CrossRef]

3. Ouyang, T.; Zhao, Z.; Su, Z.; Lu, J.; Wang, Z.; Huang, H. An integrated solution to harvest the waste heat from a large marine solid oxide fuel cell. Energy Convers. Manag. 2020, 223, 113318. [CrossRef]

4. Peng, J.; Huang, J.; Wu, X.; Xu, Y.; Chen, H.; Li, X. Solid oxide fuel cell (SOFC) performance evaluation, fault diagnosis and health control: A review. J. Power Sources 2021, 505, 230058. [CrossRef]

5. Wu, X.; Xu, Y.; Xue, T.; Shuai, J.; Jiang, J.; Fu, X.; Li, X. Control-oriented fault detection of solid oxide fuel cell system unknown input on fuel supply. Asian J. Control. 2019, 21, 1824-1835. [CrossRef]

6. Cheng, H.; Li, X.; Jiang, J.; Deng, Z.; Yang, J.; Li, J. A nonlinear sliding mode observer for the estimation of temperature distribution in a planar solid oxide fuel cell. Int. J. Hydrogen Energy 2015, 40, 593-606. [CrossRef]

7. Wu, X.; Xu, Y.; Li, D.; Zheng, Y.; Li, J.; Sorrentino, M.; Yu, Y.; Wan, X.; Hu, L.; Zou, C.; et al. Afterburner temperature safety assessment for solid oxide fuel cell system based on computational fluid dynamics. J. Power Sources 2021, 496, 229837. [CrossRef]

8. Iwata, M.; Hikosaka, T.; Morita, M.; Iwanari, T.; Ito, K.; Onda, K.; Esaki, Y.; Sakaki, Y.; Nagata, S. Performance analysis of planar-type unit SOFC considering current and temperature distributions. Solid State Ion. 2000, 132, 297-308. [CrossRef]

9. Xi, H.D.; Sun, J.; Tsourapas, V. A control oriented low order dynamic model for planar SOFC using minimum Gibbs free energy method. J. Power Sources 2007, 165, 253-266. [CrossRef]

10. Xi, H.D.; Sun, J. Dynamic analysis of planar solid oxide fuel cell models with different assumptions of temperature layers. J. Fuel Cell Sci. Technol. 2009, 6, 011011. [CrossRef]

11. Chen, B.; Xu, H.; Tan, P.; Zhang, Y.; Xu, X.; Cai, W.; Chen, M.; Ni, M. Thermal modelling of ethanol-fuelled solid oxide fuel cells. Appl. Energy 2019, 237, 476-486.

12. Yan, M.; Zeng, M.; Chen, Q.; Wang, Q. Numerical study on carbon deposition of SOFC with unsteady state variation of porosity. Appl. Energy 2012, 97, 754-762. [CrossRef]

13. Palomba, V.; Ferraro, M.; Frazzica, A.; Vasta, S.; Sergi, F.; Antonucci, V. Experimental and numerical analysis of a SOFC-CHP system with adsorption and hybrid chillers for telecommunication applications. Appl. Energy 2018, 216, 620-633. [CrossRef]

14. Palomba, V.; Ferraro, M.; Frazzica, A.; Vasta, S.; Sergi, F.; Antonucci, V. Dynamic Simulation of a Multi-Generation System, for Electric and Cooling Energy Provision, Employing a SOFC Cogenerator and an Adsorption Chiller. In Leveraging Energy Technologies and Policy Options for Low Carbon Cities; Yan, J., Ed.; Elsevier Science Bv: Amsterdam, The Netherlands, 2017; pp. $416-423$.

15. Antonucci, V.; Branchini, L.; Brunaccini, G.; De Pascale, A.; Ferraro, M.; Melino, F.; Orlandini, V.; Sergi, F. Thermal integration of a SOFC power generator and a Na-NiCl2 battery for CHP domestic application. Appl. Energy 2017, 185, 1256-1267. [CrossRef]

16. Krummrein, T.; Henke, M.; Kutne, P.; Aigner, M. Numerical analysis of operating range and SOFC-off-gas combustor requirements of a biogas powered SOFC-MGT hybrid power plant. Appl. Energy 2018, 232, 598-606. [CrossRef]

17. Lee, J.S.; Seo, J.; Kim, H.Y.; Chung, J.T.; Yoon, S.S. Effects of combustion parameters on reforming performance of a steam-methane reformer. Fuel 2013, 111, 461-471. [CrossRef]

18. Cameretti, M.C.; Pontecorvo, A.; Tuccillo, R. Performance and combustion analysis of a micro gas turbine-solid oxide fuel cell hybrid system. J. Electrochem. Energy Convers. Storage 2007, 4, 459-467. [CrossRef] 
19. Mahisanana, C.; Authayanun, S.; Patcharavorachot, Y.; Arpornwichanop, A. Design of SOFC based oxyfuel combustion systems with anode recycling and steam recycling options. Energy Convers. Manag. 2017, 151, 723-736. [CrossRef]

20. Park, S.K.; Kim, T.S.; Sohn, J.L.; Lee, Y.D. An integrated generation system combining solid oxide fuel cell and oxy-fuel combustion for high performance and CO2 capture. Appl. Energy 2011, 88, 1187-1196.

21. Mueller, F.; Fardadi, M.; Shaffer, B.; Brouwer, J.; Jabbari, F. Transient performance of integrated SOFC system including spatial temperature control. In Proceedings of the ASME 8th International Conference on Fuel Cell Science, Engineering, and Technology, Brooklyn, NY, USA, 14-16 June 2010; ASME (American Society of Mechanical Engineers): New York, NY, USA, 2010 ; pp. $237-247$.

22. Jiang, J.H.; Li, X.; Deng, Z.H.; Yang, J.; Zhang, Y.; Li, J. Thermal management of an independent steam reformer for a solid oxide fuel cell with constrained generalized predictive control. Int. J. Hydrogen Energy 2012, 37, 12317-12331. [CrossRef]

23. Yang, J.; Li, X.; Mou, H.G.; Jian, L. Predictive control of solid oxide fuel cell based on an improved Takagi-Sugeno fuzzy model. J. Power Sources 2009, 193, 699-705. [CrossRef]

24. Yang, J.; Li, X.; Mou, H.G.; Jian, L. Control-oriented thermal management of solid oxide fuel cells based on a modified TakagiSugeno fuzzy model. J. Power Sources 2009, 188, 475-482. [CrossRef]

25. Jiang, J.H.; Li, X.; Li, J. Modeling and model-based analysis of a solid oxide fuel cell thermal-electrical management system with an air bypass valve. Electrochim. Acta 2015, 177, 250-263. [CrossRef]

26. Zhang, L.; Li, X.; Jiang, J.H.; Li, S.; Yang, J.; Li, J. Dynamic modeling and analysis of a 5-kW solid oxide fuel cell system from the perspectives of cooperative control of thermal safety and high efficiency. Int. J. Hydrogen Energy 2015, 40, 456-476. [CrossRef]

27. Cao, H.L.; Li, X.; Deng, Z.H.; Li, J.; Qin, Y. Thermal management oriented steady state analysis and optimization of a kW scale solid oxide fuel cell stand-alone system for maximum system efficiency. Int. J. Hydrogen Energy 2013, 38, 12404-12417. [CrossRef]

28. $\mathrm{Wu}, \mathrm{X}$.; Gao, D. Fault tolerance control of SOFC systems based on nonlinear model predictive control. Int. J. Hydrogen Energy 2017, 42, 2288-2308. [CrossRef]

29. Polverino, P.; Pianese, C.; Sorrentino, M.; Marra, D. Model-based development of a fault signature matrix to improve solid oxide fuel cell systems on-site diagnosis. J. Power Sources 2015, 280, 320-338. [CrossRef]

30. Polverino, P.; Esposito, A.; Pianese, C.; Ludwig, B.; Iwanschitz, B.; Mai, A. On-line experimental validation of a model-based diagnostic algorithm dedicated to a solid oxide fuel cell system. J. Power Sources 2016, 306, 646-657. [CrossRef]

31. Polverino, P.; Sorrentino, M.; Pianese, C. A model-based diagnostic technique to enhance faults isolability in Solid Oxide Fuel Cell systems. Appl. Energy 2017, 204, 1198-1214. [CrossRef]

32. Nikitin, I.S.; Burago, N.G.; Zhuravlev, A.B.; Nikitin, A.Â.D. Multimode Model for Fatigue Damage Development. Mech. Solids 2020, 55, 1432-1440. [CrossRef]

33. Zhu, Z.; Li, Y.; Wang, Y.; Wang, Y.; Tong, H. A deep multimodal model for bug localization. Data Min. Knowl. Discov. 2021, 35, 1369-1392. [CrossRef]

34. Wejrzanowski, T.; Haj Ibrahim, S.; Cwieka, K.; Loeffler, M.; Milewski, J.; Zschech, E.; Lee, C.-G. Multimode porous microstructure for high temperature fuel cell application. J. Power Sources 2018, 373, 85-94. [CrossRef]

35. Yan, D.; Zhang, C.; Liang, L.; Li, K.; Jia, L.; Pu, J.; Jian, L.; Li, X.; Zhang, T. Degradation analysis and durability improvement for SOFC 1-cell stack. Appl. Energy 2016, 175, 414-420. [CrossRef] 